\title{
BMJ Open Associations between sensitisation to allergens and allergic diseases: a hospital-based case-control study in China
}

Wei Zhang (D) , ${ }^{1}$ Biao Xie, ${ }^{2}$ Meina Liu, ${ }^{1}$ Yupeng Wang ${ }^{1}$

To cite: Zhang W, Xie B, Liu M, et al. Associations between sensitisation to allergens and allergic diseases: a hospital-based case-control study in China. BMJ Open 2022;12:e050047. doi:10.1136/ bmjopen-2021-050047

- Prepublication history and additional supplemental material for this paper are available online. To view these files, please visit the journal online (http://dx.doi.org/10.1136/ bmjopen-2021-050047)

Received 10 February 2021 Accepted 11 January 2022
Check for updates

(C) Author(s) (or their employer(s)) 2022. Re-use permitted under CC BY-NC. No commercial re-use. See rights and permissions. Published by BMJ.

${ }^{1}$ Department of Biostatistics, Harbin Medical University, Harbin, Heilongjiang, China ${ }^{2}$ Department of Biostatistics, Chongqing Medical University, Chongqing, Sichuan, China

Correspondence to Dr Yupeng Wang; wangyupeng@hrbmu.edu.cn

\section{ABSTRACT}

Objectives To assess the associations of sensitisation to common allergens with atopic dermatitis, allergic rhinitis and allergic asthma in adults.

Design Case-control study.

Setting Data were collected from the First Affiliated Hospital of Harbin Medical University in Harbin, China. Participants Cases were 5111 patients with physiciandiagnosed atopic dermatitis $(n=2631)$, allergic asthma $(n=1320)$ and allergic rhinitis $(n=1160)$ recruited from the department of allergy from March 2009 to December 2017. Controls were 2576 healthy adults who underwent physical examination at the same hospital during the same period.

Main outcome measures Specific IgE levels to 16 common food, indoor and outdoor allergens were assessed in all participants. Adjusted ORs and 95\% Cls for the association between allergen sensitisation and allergic diseases were estimated using multivariate logistic regression.

Results The prevalence of allergen sensitisation was higher in patients with atopic dermatitis (indoor $=17.14 \%$, outdoor $=12.85 \%$, food $=21.44 \%$ ), allergic rhinitis (indoor $=23.18 \%$, outdoor $=26.81 \%$, food $=8.94 \%$ ) and allergic asthma (indoor $=24.65 \%$, outdoor $=16.46 \%$, food $=14.31 \%$ ) compared with controls (indoor $=11.03 \%$, outdoor $=6.84 \%$, food $=5.83 \%$ ). After adjustment for potential confounding variables, there was a doseresponse relevance between the levels of allergen-specific $\lg \mathrm{E}$ and allergic diseases ( $\mathrm{p}$ trend $<0.0001$ ). The number of allergens to which a patient was sensitised increased the risk of allergic diseases (atopic dermatitis: highest adjusted $\mathrm{OR}=4.28,95 \% \mathrm{Cl} 2.57$ to 7.11 ; allergic rhinitis: highest adjusted $\mathrm{OR}=13.00,95 \% \mathrm{Cl} 3.76$ to 45.00 ; allergic asthma: $\mathrm{OR}=2.37,95 \% \mathrm{Cl} 1.67$ to 3.37 ).

Conclusion There was a dose-response relevance between levels of allergen-specific $\lg E$ and allergic diseases' prevalence, and multiple sensitisations increased the risk of allergic diseases. This study provides evidence for the prophylaxis of allergic diseases.

\section{INTRODUCTION}

Allergic diseases are global and can profoundly affect the quality of life of patients. ${ }^{1}$ The incidence of allergic diseases, including atopic dermatitis, allergic rhinitis

\section{Strengths and limitations of this study}

- We assessed the dose-response relationship between allergen-specific $\lg E$ levels to 16 different allergens and prevalence of allergic diseases using logistic regressions.

- Various types of allergens were considered and categorised into indoor, outdoor and food allergens.

- Adjusted ORs and 95\% Cls for the association between allergen sensitisation and allergic diseases were estimated using multivariate logistic regression.

- The combined effects of multiple allergens on allergic diseases were inspected through multivariate logistic regression analyses, which were conducted with different number of sensitising allergens $(1,2$, $\geq 3$ allergens).

- Although this was not a multicentre study, it was a population-based study with a large sample size.

and allergic asthma, has been increasing rapidly around the world, especially in China and other low-income and middle-income countries. ${ }^{2-4}$ As triggering factors, allergens stimulate the body to produce abnormal immune responses, which eventually lead to allergic diseases. ${ }^{5}$ The type and dose of allergens determine the type of allergic disease and its severity. ${ }^{6}$ Therefore, it is crucial to clarify the distributions of positive allergens among patients with different allergic diseases.

Currently, many studies have been devoted to explore the association between sensitisation to allergens and allergic diseases. Gray et al randomly enrolled 100 children aged 6 months to 10 years with atopic dermatitis and found that a high prevalence of egg sensitisation of $54 \%$, and Skin Prick Test (SPT) to fresh egg white showed a high predictive value for egg allergy. ${ }^{7}$ A Japanese study explored the causal relationships among pollen counts, tweet numbers and patient numbers for seasonal allergic rhinitis and 
reported a positive correlation between pollen counts and the patient numbers. ${ }^{8}$ Sensitisation and exposure to indoor allergens (such as dust mites, cockroaches, wild rodents, pets and fungi) have been reported to be associated with allergic diseases, especially the development of asthma. ${ }^{9}$ Patients with allergies usually have different levels of specific IgE to a certain allergen and allergens are often coexistent, so it is critical to understand the associations between multiple allergens sensitisation and allergic diseases. ${ }^{10}$ According to previous studies, the incidence of allergic diseases varies among different geographical locations and subpopulations. For Koreans, high sensitisations to various types of pollen were in the Gangwon region, whereas sensitisation to Japanese cedar pollen was unique in the Jeju region. ${ }^{11}$ Among the individuals from the Americas, grass pollen and animal dander allergies were relatively common, while weed and grass pollen allergies were common in people from Central Asia. ${ }^{11}$ Therefore, it is suggested that genetic and environmental features may play important roles in allergic diseases, and it is interesting to understand the underlying causes of those variations. At present, most relevant studies have a limited sample size, and few such studies have been conducted in northeastern China with its distinctive environmental and climate conditions. ${ }^{12-14}$

In the present study, we assessed the associations between sensitisation to 16 allergens and three common allergic diseases in northeastern China and explored if there is a dose-response connection between the specific IgE levels to an allergen and of allergic diseases' prevalence. We also examined the combined effects of multiple allergens on a specific allergic disease. Our study aimed to supply basis for the prevention and management of allergic diseases.

\section{MATERIALS AND METHODS}

\section{Participants and public involvement}

Harbin is located in northeast of China with longitude spanning $125^{\circ} 42^{\prime}-130^{\circ} 10^{\prime} \mathrm{E}$ and latitude $44^{\circ} 04^{\prime}-46^{\circ} 40^{\prime}$ $\mathrm{N}$, which is the provincial capital of Heilongjiang Province. Under the direct influence of the Siberian Anticyclone, the average daily temperature is $-19.7^{\circ} \mathrm{C}(-3.5)$ in winter. Annual low temperatures below $-35.0^{\circ} \mathrm{C}(-31.0)$ are not uncommon. Nicknamed 'Ice City' due to its freezingly cold winter. We recruited the participants into our research from Harbin. Only those who signed the informed consent form were recruited into our study. This project was authorised by the Institutional Review Board of Harbin Medical University. Adult patients aged 18 years or older with one of the three common allergic diseases (atopic dermatitis, allergic asthma or allergic rhinitis), who visited the Department of Allergy of the First Affiliated Hospital of Harbin Medical University during March 2009 and December 2017, were collected as the candidate cases. Healthy adults without any clinical symptoms and diseases who underwent physical examination at the same hospital during the same period were recruited as the candidate controls. All participants carried on allergen-specific IgE tests to 16 kinds of allergens and a questionnaire investigation.

\section{Allergen-specific IgE testing}

Serum allergen-specific IgE concentrations of 16 common allergens were measured in all eligible participants using the AllergyScreen system (Mediwise Analytic $\mathrm{GmbH}$, Germany). As shown in online supplemental information, the 16 allergens were defined as three types: indoor allergens, outdoor allergens and food allergens. ${ }^{15}$ Based on previous research, allergen-specific $\operatorname{IgE}>0.35 \mathrm{kU} / \mathrm{L}$ was considered as allergen sensitisation in this study, and specific IgE concentration of $0.35-0.70 \mathrm{kU} / \mathrm{L}$ was defined as class $1,0.70-3.50 \mathrm{kU} / \mathrm{L}$ as class 2 and $>3.50 \mathrm{kU} / \mathrm{L}$ as class $3 .^{16}$

\section{Allergic diseases definition}

We focused on three common allergic diseases (atopic dermatitis, allergic asthma and allergic rhinitis) in Harbin. The three allergic diseases are diagnosed by experienced physicians using existing benchmarks for atopic dermatitis ${ }^{17}$ allergic rhinitis ${ }^{18}$ and allergic asthma. ${ }^{19}$ The detailed diagnostic criteria are shown in online supplemental information. Besides, the following criteria should be obeyed:

1. There were at least have one positive outcome of the 16 allergen-specific IgE results.

2. The patients had been diagnosed with one of the allergic diseases using current guidelines mentioned above.

\section{Demographic, lifestyle characteristics and family history}

All of the participants in this study answered the questionnaire face to face to collect data on demographic, lifestyle characteristics and family history. Gender, age, level of education, residential region and marital status were analysed as demographic characteristics. Smoking, drinking and physical exercise were included in lifestyle factors. The definition of those factors is shown in the online supplemental information.

\section{Statistical analysis}

To assess the dose-response relationship between levels of allergen-specific $\mathrm{IgE}$ to 16 different allergens and prevalence of allergic diseases, we applied logistic regressions to evaluate the ORs and their CIs. Multivariate logistic regression models were adjusted for potential confounding variables significantly associated with allergic diseases identified from univariate analysis or as suggested in previous literature. They included gender, age, BMI (body mass index: weight (in $\mathrm{kg}$ ) $/$ height $^{2}$ (in $\left.\mathrm{m}^{2}\right)$ ), level of education, smoking, drinking, living region, marital status, family history of allergic diseases, physical exercise and other 15 allergen-specific IgE responses. To inspect the combined effects of multiple allergens on allergic diseases, multivariate logistic regression analyses were conducted with different number of sensitising allergens (1, 2, $\geq 3$ allergens). The statistical analysis software 


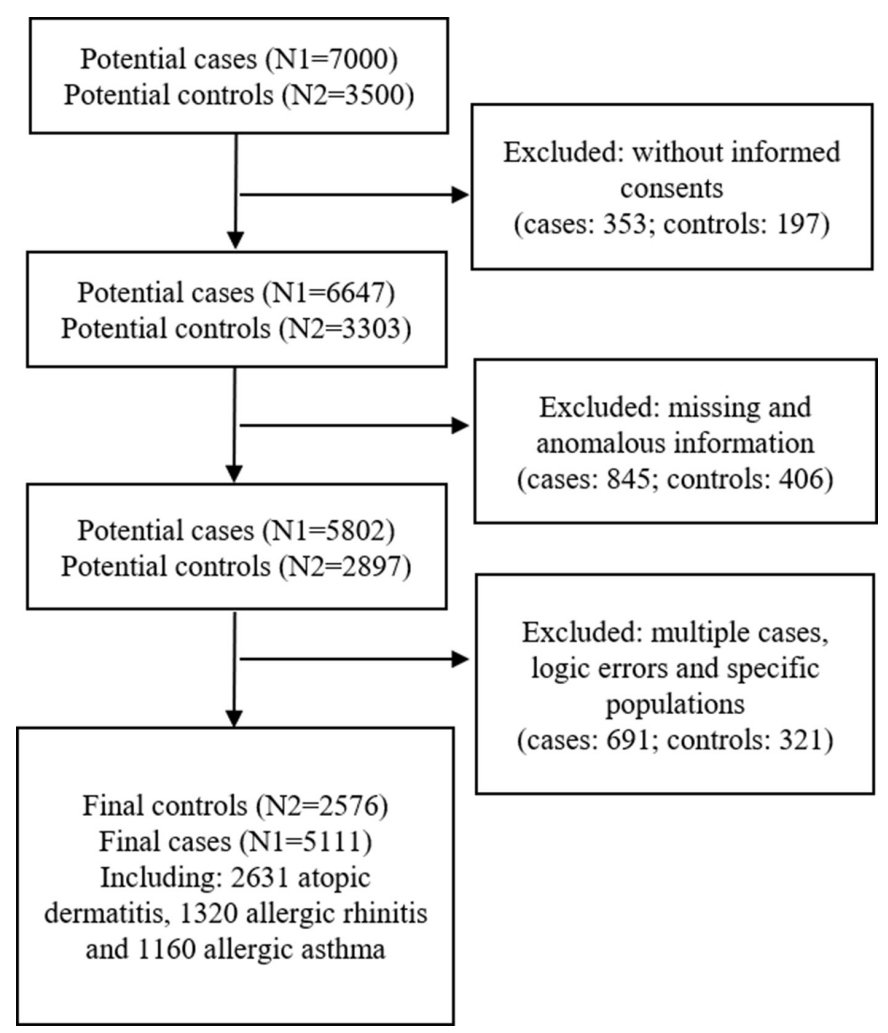

Figure 1 The flow diagram of study participants.

of this study was SAS V.9.1 (SAS Institute, Cary, North Carolina).

\section{RESULTS}

\section{Participants}

In the present study, 7000 candidate cases and 3500 candidate controls were initially recruited. Excluding those without written informed consents, 6647 candidate cases and 3303 candidate controls remained. After excluding those with missing values and logic errors, and some special populations (sportsmen, pregnant or lactating women), we had 5111 cases (2631 atopic dermatitis, 1320 allergic rhinitis and 1160 allergic asthma) and 2576 controls for our final analysis. The flow diagram of the screening process of study participants is summarised in figure 1.

\section{Characteristics in cases and controls}

There are statistical differences between patients with atopic dermatitis and controls in terms of gender, age, height, weight, BMI, residential region, smoking, education and family history $(\mathrm{p}<0.05)$. Patients with allergic rhinitis were significantly different from controls in gender, height, weight, BMI, education and family history $(p<0.05)$. Gender, age, weight, BMI, residential region, smoking, levels of education, marital status and physical exercise were different between those with allergic asthma and controls $(\mathrm{p}<0.05)$. Detail demographic characteristics are summarised in table 1 .
Prevalence of allergen sensitisation in patients with atopic dermatitis, allergic rhinitis and allergic asthma

Patients with different allergic diseases had different prevalence of allergens sensitisation. Among patients with atopic dermatitis, the prevalence of food allergens sensitisation was higher than other allergens. The prevalence of outdoor allergens sensitisation was higher in those with allergic rhinitis while that of indoor allergens was higher in patients with allergic asthma (figure 2).

Adjusted for gender, age, BMI, level of education, smoking, drinking, living region, family history, physical exercise and other 15 allergen-specific IgE responses, specific IgE to common ragweed and mugwort, Dermatophagoides pteronyssinus, dog fur and cat fur were significantly related to the risk of allergic asthma (tables 2 and 3). Allergic rhinitis was significantly associated with common ragweed and mugwort, mould mixture, tree pollen mixture and Hop (table 3), while atopic dermatitis was significantly associated with egg white/egg yolk, crab, blue mussel, milk, fish and shrimp (tables 4 and 5). There was a dose-response relationship between specific IgE levels, from class 1 to class 3 , and the prevalence of allergic diseases, the prevalence of allergic diseases increased along with the increasing levels of allergenspecific IgE to allergens ( $p$ trend $<0.0001)$.

\section{Combined effects of sensitization to multiple allergens on allergic diseases}

ORs and their 95\% CIs of allergic diseases with the different number of allergens are shown in table 6 . Although the three allergic diseases had different ORs and 95\% CI, the patterns of the relationships between allergic diseases and the number of allergens were similar. ORs increased as the number of sensitive allergens increased ( $p$ trend $<0.0001$ ). The associations between two or more allergens and atopic dermatitis were strong, adjusted $\mathrm{OR}=4.28$ (95\% CI 2.57 o 7.11). The combination of specific IgE to three or more sensitive allergens possessed the highest $\mathrm{OR}$ for allergic rhinitis (adjusted $\mathrm{OR}=13.00$, 95\% CI 3.76 to 45.00 ), while the combination of specific IgE to two or more allergens showed the highest OR for allergic asthma (adjusted $\mathrm{OR}=2.37$, 95\% CI 1.67 to 3.37).

\section{DISCUSSION}

In our present hospital-based case-control research, we found that different allergens are significantly related to different allergic diseases. There is a dose-response relationship between allergen-specific IgE levels and allergic diseases, and multiple sensitisations increase the risk of allergic diseases. The incidence of allergic diseases has increased rapidly worldwide. ${ }^{2-4}$ The World Allergy Organization reported that, among 1.39 billion people in 33 countries, $22 \%$ of the population suffered from allergic diseases. ${ }^{20}$ The WHO has clearly stipulated that allergic disease is an extremely considerable disease that the whole world should attach importance to. ${ }^{21}$ Identifying specific allergens that trigger allergic diseases is 
Table 1 Characteristics of patients with atopic dermatitis, allergic rhinitis, allergic asthma and controls.

\begin{tabular}{|c|c|c|c|c|c|c|c|}
\hline & Control & $\begin{array}{l}\text { Atopic } \\
\text { dermatitis }\end{array}$ & $\mathbf{P}^{*}$ & Allergic rhinitis & $\mathbf{P}^{*}$ & Allergic asthma & $\mathbf{P}^{*}$ \\
\hline Number & 2576 & 2631 & & 1320 & & 1160 & \\
\hline Men, n (\%) & 732 (28.42) & $684(26.00)$ & 0.0499 & $532(40.30)$ & $<0.0001$ & 398 (34.31) & 0.0003 \\
\hline Age, years $\dagger$ & $34.96(16.13)$ & $36.70(15.33)$ & $<0.0001$ & 34.59 (13.76) & 0.4868 & 41.60 (17.25) & $<0.0001$ \\
\hline Height, $\mathrm{cm} \dagger$ & $160.40(14.71)$ & $163.00(11.14)$ & $<0.0001$ & $164.90(11.07)$ & $<0.0001$ & $160.90(14.59)$ & 0.3205 \\
\hline Weight, $\mathrm{kg} \dagger$ & $58.43(15.95)$ & $60.34(13.70)$ & $<0.0001$ & 62.49 (15.22) & $<0.0001$ & $60.02(15.20)$ & 0.0041 \\
\hline $\mathrm{BMI}, \mathrm{kg} / \mathrm{m}^{2} \dagger$ & $22.26(4.17)$ & $22.51(3.95)$ & 0.0268 & $22.71(3.98)$ & 0.0009 & $22.79(4.04)$ & 0.0003 \\
\hline Rural, n (\%) & $750(29.12)$ & $1020(38.75)$ & $<0.0001$ & 374 (28.32) & 0.6533 & $416(35.88)$ & 0.0003 \\
\hline Married, n (\%) & 1661 (64.49) & $1708(64.92)$ & 0.8370 & 875 (66.31) & 0.4722 & $891(76.85)$ & $<0.0001$ \\
\hline smoking, n (\%) & $338(13.12)$ & 437 (16.61) & 0.0004 & $194(14.70)$ & 0.1752 & $296(25.52)$ & $<0.0001$ \\
\hline $\begin{array}{l}\text { Alcohol } \\
\text { drinking, n (\%) }\end{array}$ & 317 (12.31) & 349 (13.26) & 0.3002 & $192(14.55)$ & 0.0496 & $156(13.45)$ & 0.3313 \\
\hline $\begin{array}{l}\text { Physical } \\
\text { exercise, n (\%) }\end{array}$ & $893(34.68)$ & 897 (34.08) & 0.7735 & $490(37.15)$ & 0.3281 & $319(27.52)$ & 0.0015 \\
\hline \multicolumn{8}{|l|}{ Education, n (\%) } \\
\hline $\begin{array}{l}\text { Junior high } \\
\text { school or } \\
\text { lower }\end{array}$ & $1253(48.64)$ & $1084(41.20)$ & $<0.0001$ & $459(34.77)$ & $<0.0001$ & $610(52.59)$ & 0.0220 \\
\hline $\begin{array}{l}\text { Senior high } \\
\text { school }\end{array}$ & 618 (23.99) & 734 (27.90) & & $315(23.86)$ & & $280(24.14)$ & \\
\hline $\begin{array}{l}\text { University or } \\
\text { higher }\end{array}$ & 705 (27.37) & $813(30.90)$ & & $546(41.36)$ & & $270(23.28)$ & \\
\hline $\begin{array}{l}\text { Family history, } \\
\mathrm{n}(\%)\end{array}$ & $452(17.55)$ & $1937(26.38)$ & $<0.0001$ & $379(28.71)$ & $<0.0001$ & $202(17.41)$ & 0.9213 \\
\hline
\end{tabular}

${ }^{*} \mathrm{P}$ values comparing cases with controls.

†The quantitative variables were expressed as means and their SD.

BMI, body mass index.

particularly significant for the prophylaxis and treatment of allergic diseases.

Our findings indicated that atopic dermatitis was significantly related to food allergen sensitisation, while allergic rhinitis and allergic asthma were significantly associated

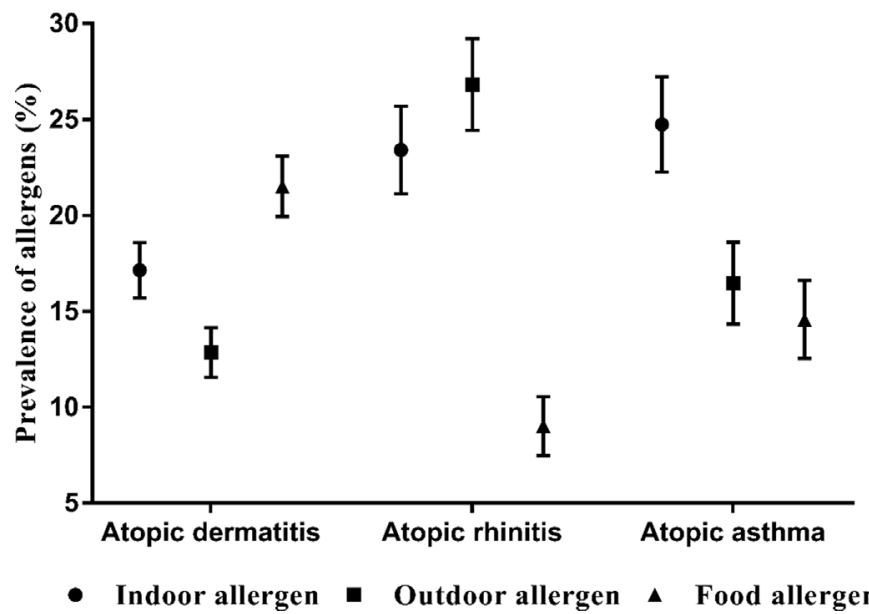

Figure 2 Prevalence of allergens sensitisation among patients with atopic dermatitis, allergic rhinitis and allergic asthma. with both indoor and outdoor allergen sensitisation. The recognition to food allergens through antigen-presenting cells in eczematous skin plays an important role in the link between food allergy and allergic dermatitis. In addition, the dysfunction of filaggrin or Th2-related cytokines or rare genetic syndromes may also involve in the mechanism. ${ }^{22}$ Different types of allergens induce different allergic diseases, which may due to the properties or size of allergens. Allergic rhinitis is associated with outdoor allergens, mainly pollen, probably because pollen particles are slightly larger than indoor dust and are more likely to stay in the nose. ${ }^{23}$ Inhalation of indoor dust, mites and fungi can increase the airway reactivity and causes allergic asthma. ${ }^{24}$ Our findings were consistent with previous studies that sensitisation to indoor allergens is important risk factors in patients with allergic rhinitis and allergic asthma. ${ }^{925}{ }^{26}$ Some studies also stated that there was a relevance between sensitisation to outdoor allergens and allergic rhinitis and allergic asthma. ${ }^{27-29}$ Food allergens were found to be crucial in the development of atopic dermatitis in some observations. ${ }^{2930}$ Allergens, commonly proteins, induce allergic diseases through complex interactions with the immune system. Due to the presence of 


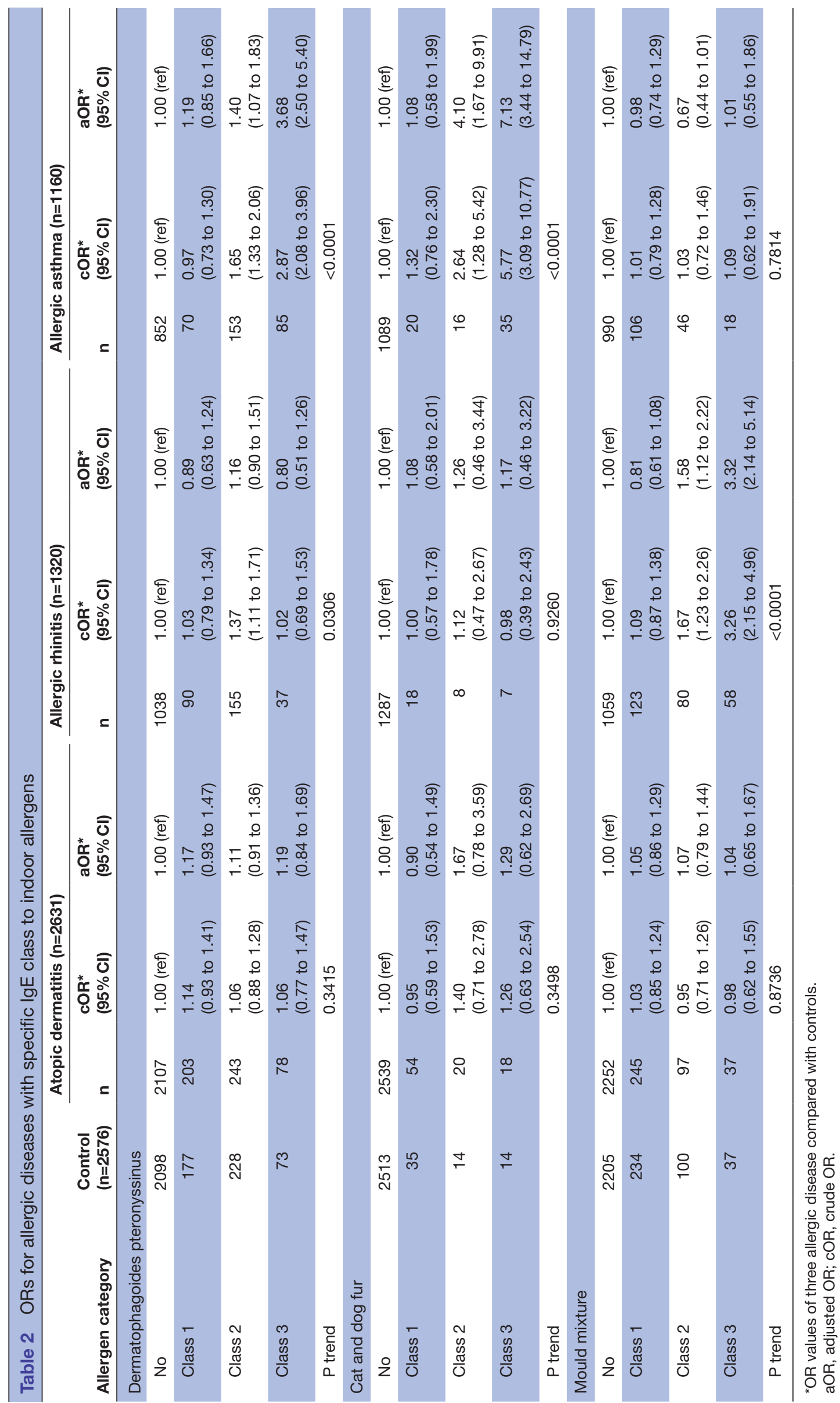




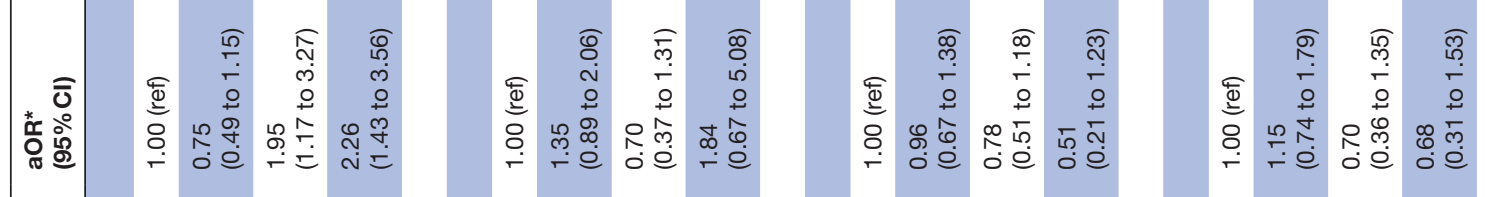

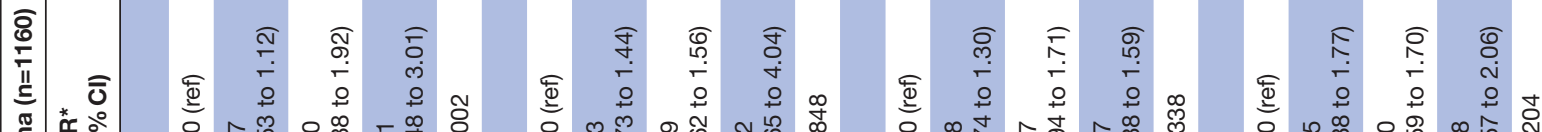

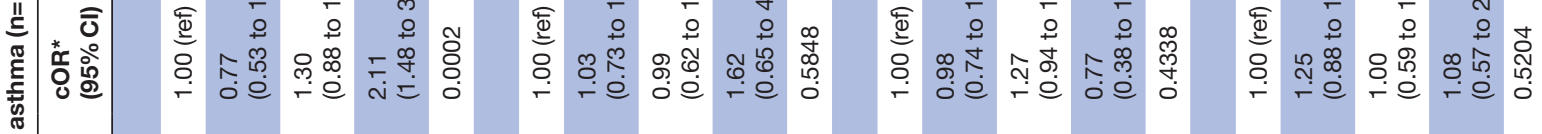

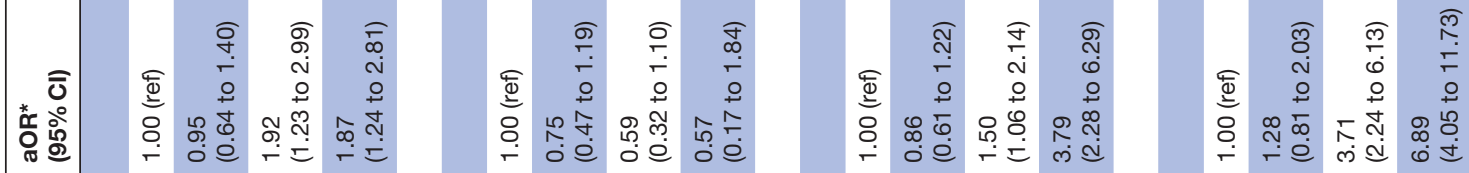

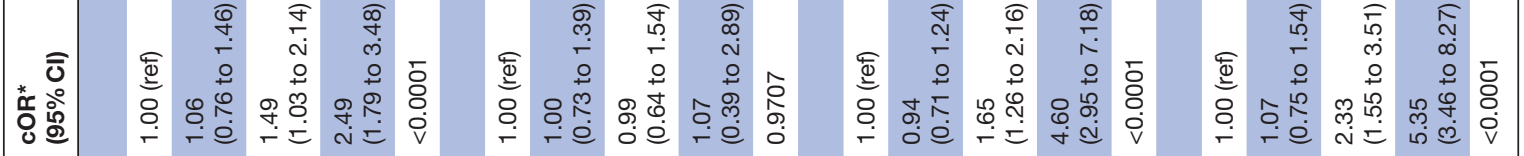

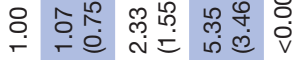

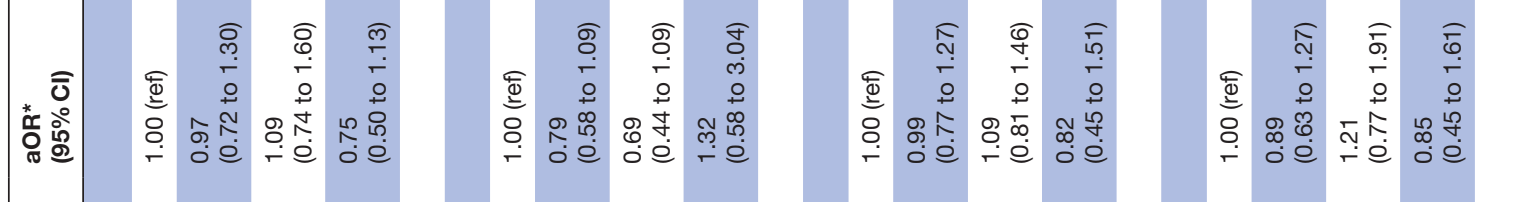

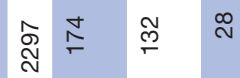

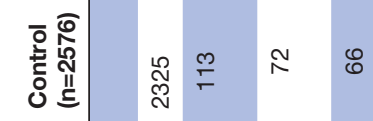

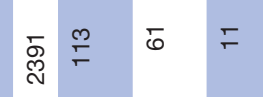

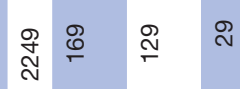
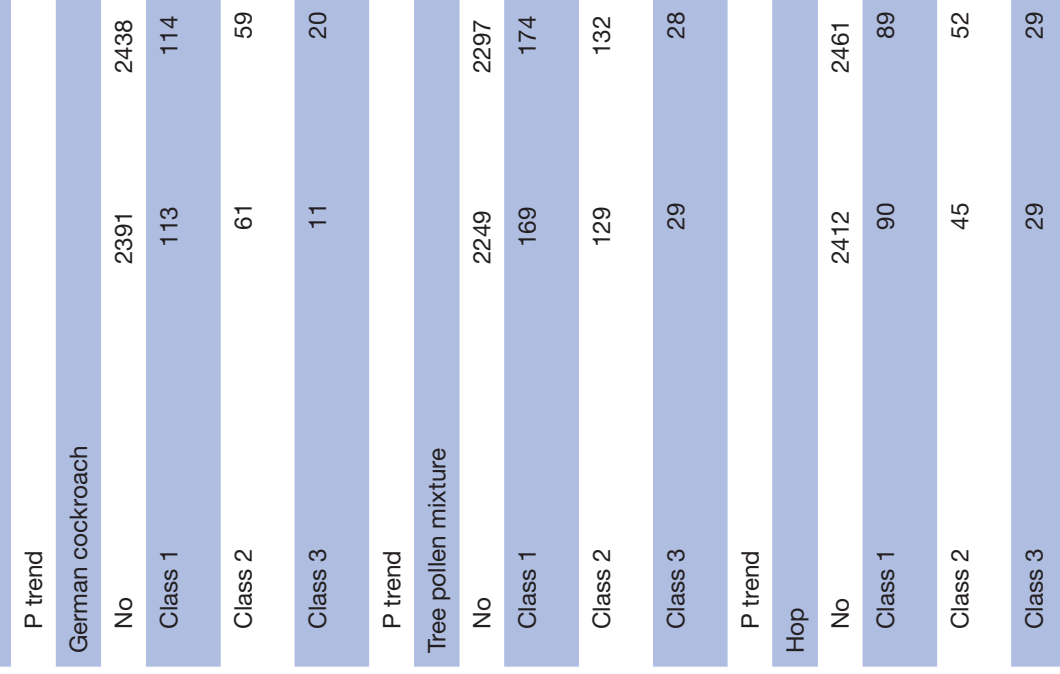


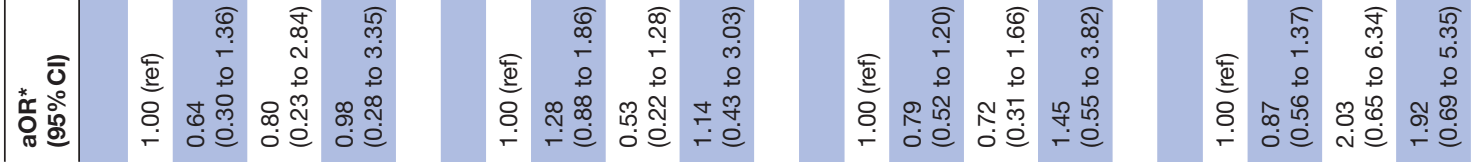

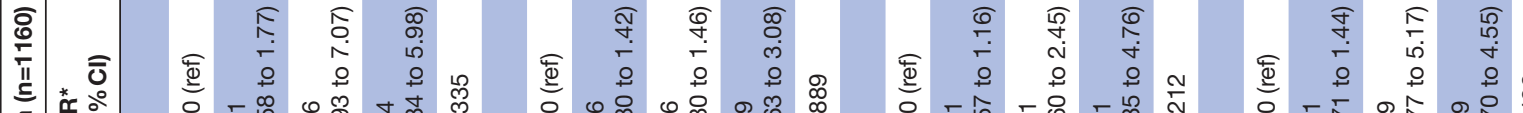

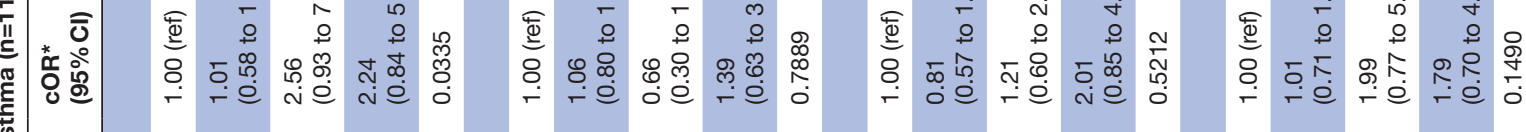

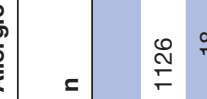

$\underset{\stackrel{0}{\circ}}{\stackrel{1}{\circ}}$

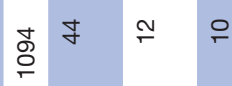

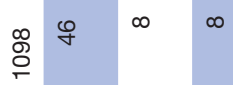

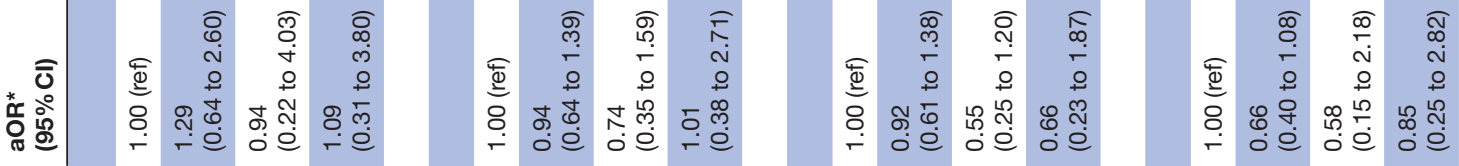

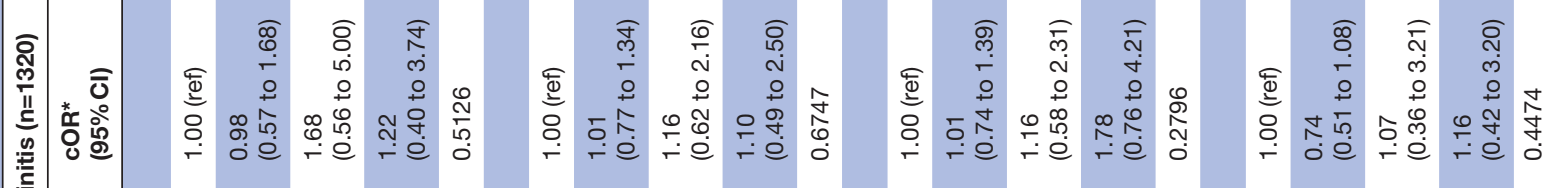

$=$

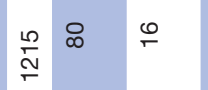

$\stackrel{\mathscr{N}}{\sim} \stackrel{m}{\leftarrow}$

$\stackrel{\text { ำ }}{\stackrel{1}{\circ}}$

(2)

○

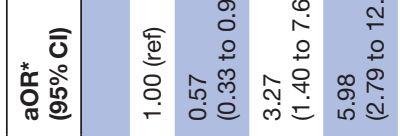

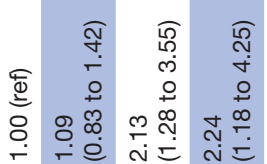

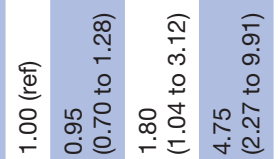

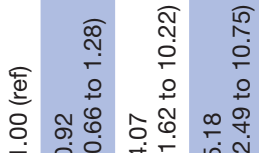

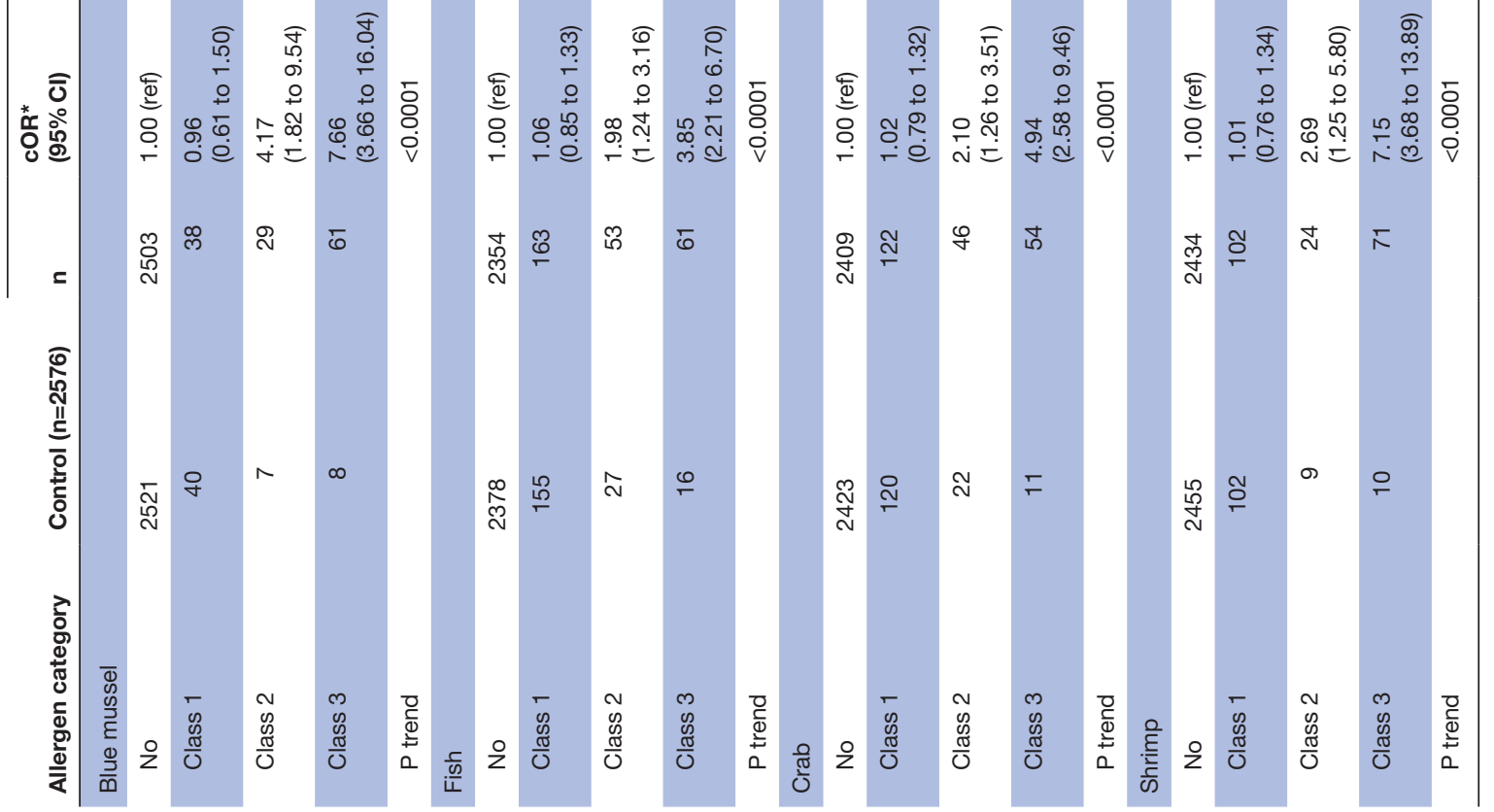

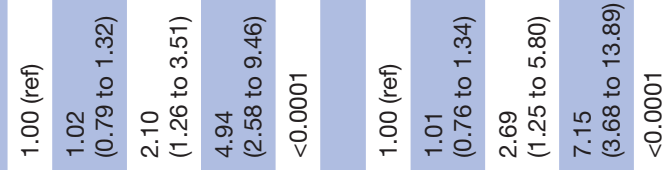




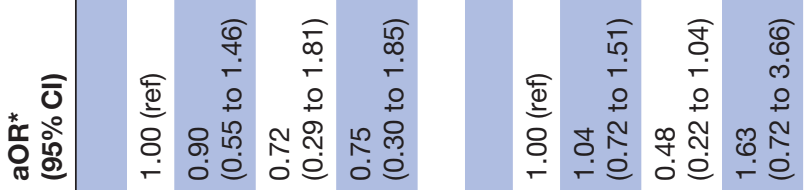

맘ำ

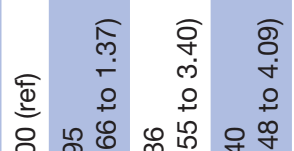

묻

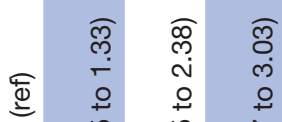

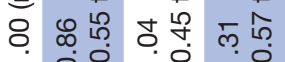

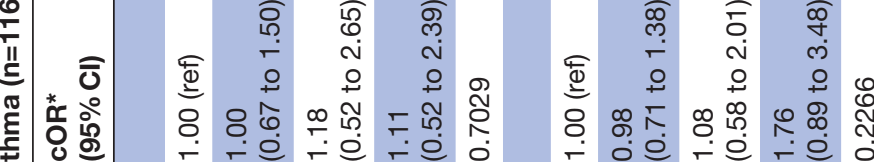

密

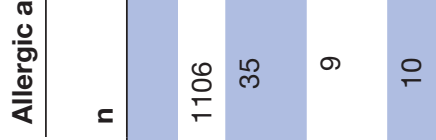

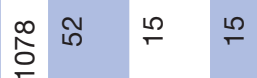

용 요 우 우

응 ले

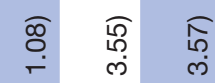

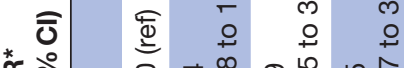

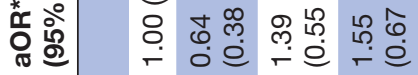

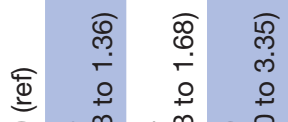

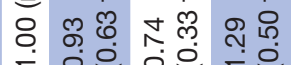

लำ ธิ

बิ

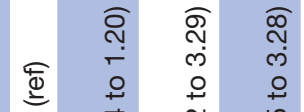

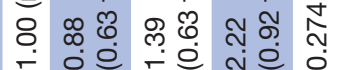

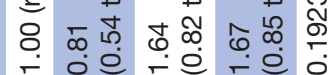

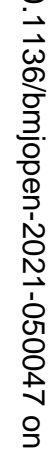

స్ํำ

\section{ঙั}

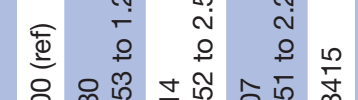

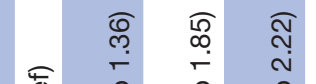

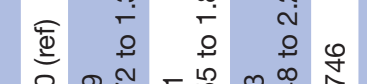

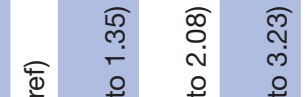

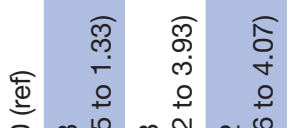

○

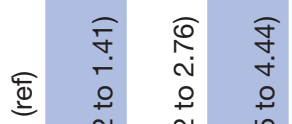

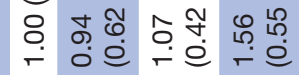

쏭

욜

웅

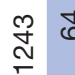

$\stackrel{\stackrel{\leftrightarrow}{N}}{\stackrel{\infty}{\sigma} \mp \quad \digamma}$

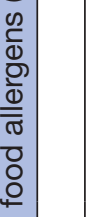

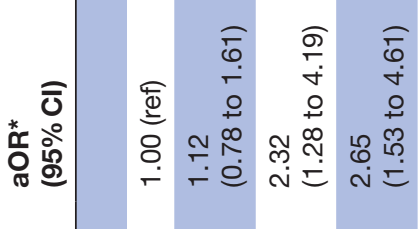

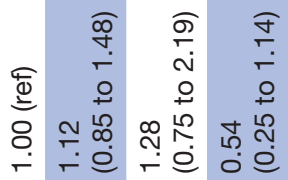

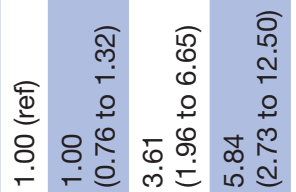

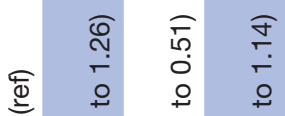

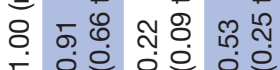

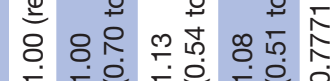

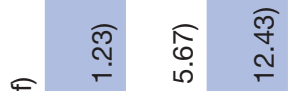

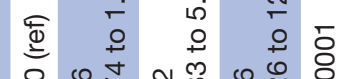

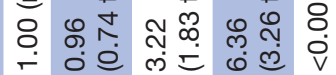

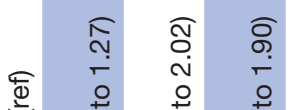

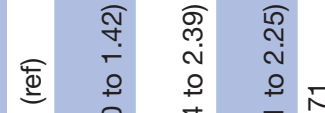

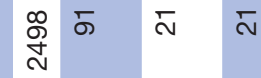




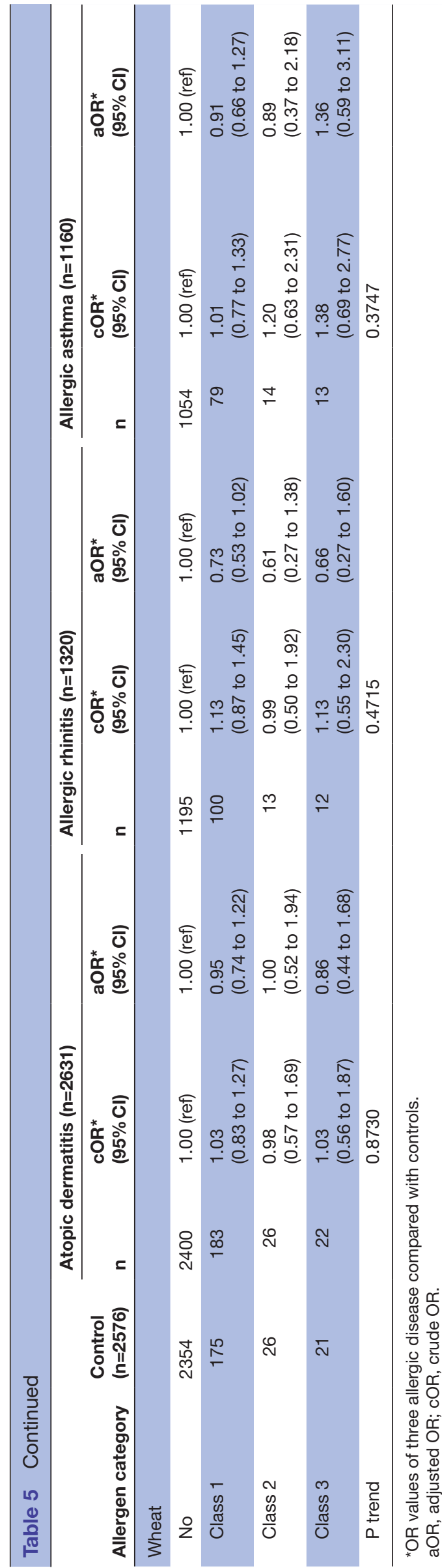

epitopes with allergenic potential, glycosylation status, resistance to proteolysis and enzymatic activity, some proteins are more allergenic than others and different allergens may cause different allergic diseases through various underlying mechanisms. ${ }^{31}$ However, some studies showed inconsistent findings. Several studies showed that indoor allergens have a bearing on the prevalence of atopic dermatitis in some individuals. ${ }^{32} 33$ Other studies showed a relationship between sensitisation to food allergens and allergic rhinitis and allergic asthma. ${ }^{34}$ The inconsistency of those studies may be related to regional variation and different climate characteristics, which affect the morphology of the allergen-carrying agents and modify their allergenic potential. ${ }^{35}{ }^{36}$ In addition, genetic susceptibility and socioeconomic status of the populations may influence the occurrence of allergic diseases. ${ }^{3} 3738$

This study revealed that there was a dose-response relationship between specific IgE levels of allergens and prevalence of allergic diseases, in which the odds of allergic diseases increase with increasing allergen-specific IgE levels. Our findings are in line with a study in America revealing a dose-response relationship between exposure to mouse allergen and the morbidity of allergic asthma in urban children and adolescents. ${ }^{39}$ Another research evaluated that whether TPI ASM8 (a drug product containing two antisense oligonucleotides: TOP004 directed against the human beta subunit of IL-3, IL-5, and GM-CSF receptors and TOP005 directed against the human chemokine receptor CCR3) induced a dose-dependent reduction in the inflammatory and physiological changes following inhaled allergen challenge. ${ }^{40}$ It is worth noting that there was a combined effect of sensitisation to different allergens on allergic diseases. Multiple sensitisations to several allergens had a relatively stronger association with allergic diseases than single sensitisation to one allergen. Some research results were similar to our findings. Kumar et al reported that simultaneous sensitisation to food and inhalant allergens (insect and pollen) may increase the risk of asthma and rhinitis or exacerbate symptoms. ${ }^{41}$ A cross-sectional population-based case-control study in Finland adults found that the pathomechanisms of sensitisation to one allergen are different from those of sensitisation to several allergen types, and the latter are more likely to induce asthma. ${ }^{42}$ In addition, most allergens were significantly associated with allergic diseases only when their IgE level classes $\geq 2$ according to our study. Such findings may be of more clinical value than a dichotomous designation of sensitised or not sensitised to allergens and can potentially be used for improving the diagnosis of allergic diseases.

According to the previous studies, genetic and environmental factors play important roles in sensitisation to allergens. ${ }^{18}{ }^{43-46}$ In our study, the family history of atopic dermatitis and allergic rhinitis were significantly different compared with the controls, while there was no difference in family history between allergic asthma and controls. The proportion living in rural was significantly higher in patients with atopic dermatitis and allergic asthma than 
Table 6 ORs for allergic diseases in relation to number of allergens

\begin{tabular}{|c|c|c|c|c|}
\hline & Control (n=2576) & $\mathbf{n}$ & $\begin{array}{l}\text { cOR* }^{*} \\
(95 \% \mathrm{Cl})\end{array}$ & $\begin{array}{l}\text { aOR* } \\
(95 \% \mathrm{CI})\end{array}$ \\
\hline & & \multicolumn{3}{|c|}{ Atopic dermatitis $(n=2631)$} \\
\hline No & 2422 & 2142 & 1.00 (ref) & 1.00 (ref) \\
\hline 1 & 135 & 375 & 3.14 (2.56 to 3.86$)$ & 3.00 (2.44 to 3.69$)$ \\
\hline$\geq 3$ & 0 & 35 & - & - \\
\hline \multirow[t]{2}{*}{$\mathrm{P}$ trend } & \multicolumn{4}{|c|}{$<0.0001$} \\
\hline & \multicolumn{4}{|c|}{ Allergic rhinitis $(n=1320)$} \\
\hline \multicolumn{5}{|c|}{ Number of allergens $\ddagger$} \\
\hline No & 2181 & 893 & 1.00 (ref) & 1.00 (ref) \\
\hline \multirow[t]{2}{*}{$\mathrm{P}$ trend } & \multicolumn{4}{|c|}{$<0.0001$} \\
\hline & \multicolumn{4}{|c|}{ Allergic asthma $(n=1160)$} \\
\hline \multicolumn{5}{|c|}{ Number of allergens§ } \\
\hline No & 2183 & 845 & 1.00 (ref) & 1.00 (ref) \\
\hline 1 & 319 & 243 & 1.97 (1.64 to 2.37$)$ & 2.06 (1.70 to 2.49$)$ \\
\hline 2 & 74 & 68 & 2.37 (1.69 to 3.33$)$ & 2.37 (1.67 to 3.37$)$ \\
\hline$\geq 3$ & 0 & 4 & - & - \\
\hline$P$ trend & \multicolumn{4}{|c|}{$<0.0001$} \\
\hline
\end{tabular}

${ }^{*}$ OR values of three allergic disease compared with controls.

†Allergens excluding those allergens which were not related with atopic dermatitis in tables 2-5. $\ddagger$ Allergens excluding those allergens which were not related with allergic rhinitis in tables 2-5 §Allergens excluding those allergens which were not related with allergic asthma in tables 2-5. aOR, adjusted OR; cOR, crude OR.

controls, while there was no difference in location of residence between allergic rhinitis and controls. We can investigate the family history and location of residence and combine clinical symptoms to speculate whether the patients are likely to be sensitive to allergens and recommend further appropriate testing.

It is obvious that allergens avoidance is the most effective means of prevention for allergy sufferers considering that allergic diseases are triggered by those allergens. However, this may not be true in some cases. Completely avoiding contact with some indoor and outdoor allergens is not always feasible. Moreover, early exposure to food allergens has been turned out to be a successful method for the prevention of peanut allergy. ${ }^{47}$ Many studies reported that allergen immunotherapy was an effective treatment strategy for allergic diseases. ${ }^{48} 49$ However, for some patients with severe symptoms, allergen avoidance and treatment of symptoms may be necessary. Our findings could provide some evidence for clinicians about avoidance or specific immunotherapy treatment for patients with allergic diseases.
There are several strengths in this study. First, the sample size of this study was relatively large, which enabled us to classify specific IgE levels of 16 common allergens into three levels: class 1, class 2 and class 3 . This enabled us to analyse the dose-response relationship between specific IgE levels and the prevalence of allergic diseases and the combined effect of sensitisation to multiple allergens with allergic diseases. Second, the 16 allergens were categorised into three categories: indoor allergens, outdoor allergens and food allergens, and the associations between each type of allergens and different allergic diseases were analysed. However, there are some limitations in this study. First, we cannot determine when the patients were first sensitised to allergens or when they first developed an allergic disease. We did not collect the specific date of the patient's visit to the hospital, so we could not analyse the impact of seasonal factors on allergic diseases. Second, this study was performed only in one hospital in Harbin, the generalisability of our results to the whole of China still needs to be further explored. 
In conclusion, food allergen sensitisation is associated with atopic dermatitis, while indoor and outdoor allergen sensitisations are related to allergic rhinitis and asthma in northeastern China. There is a dose-response relationship between allergen-specific IgE levels and allergic diseases, and multiple sensitisations increase the risk of allergic diseases. Our findings could provide evidence for the control and management of allergic diseases, and may have important public health implications.

Contributors WZ and BX designed the process of this study and the structure of this article. YW and ML designed the questionnaire. WZ and BX participated in case collection and questionnaire investigation and analysed the data. WZ wrote the manuscript, and all other authors read and confirmed the final version. YW is responsible for the overall content as guarantor.

Funding This article was supported by the Youth Science Foundation Project of the National Natural Science Foundation of China (82003556) and the National Science and Technology Major Project of China (2016Z×08011005).

Competing interests None declared.

Patient consent for publication Not applicable.

Ethics approval This study involves human participants but participants were not subjected to intervention and gave informed consent to participate in the study before taking part, so the Institutional Review Board (IRB) of Harbin Medical University exempted our study according to the regulations of our school, exempted this study. Participants gave informed consent to participate in the study before taking part.

Provenance and peer review Not commissioned; externally peer reviewed.

Data availability statement No data are available.

Supplemental material This content has been supplied by the author(s). It has not been vetted by BMJ Publishing Group Limited (BMJ) and may not have been peer-reviewed. Any opinions or recommendations discussed are solely those of the author(s) and are not endorsed by BMJ. BMJ disclaims all liability and responsibility arising from any reliance placed on the content. Where the content includes any translated material, BMJ does not warrant the accuracy and reliability of the translations (including but not limited to local regulations, clinical guidelines, terminology, drug names and drug dosages), and is not responsible for any error and/or omissions arising from translation and adaptation or otherwise.

Open access This is an open access article distributed in accordance with the Creative Commons Attribution Non Commercial (CC BY-NC 4.0) license, which permits others to distribute, remix, adapt, build upon this work non-commercially, and license their derivative works on different terms, provided the original work is properly cited, appropriate credit is given, any changes made indicated, and the use is non-commercial. See: http://creativecommons.org/licenses/by-nc/4.0/.

ORCID iD

Wei Zhang http://orcid.org/0000-0002-1199-8924

\section{REFERENCES}

1 Ana B, de la Torre F, EpidMite Study Group. Characteristics, quality of life and control of respiratory allergic diseases caused by house dust mites (HDMs) in Spain: a cross-sectional study. Clin Trans/ Allergy 2019;9:39.

2 Tremlett $\mathrm{H}$, Rodney R, Lucas $\mathrm{R}$. Can falling infection rates in one country explain rising incidence of autoimmune and allergic diseases in other countries? caution when (over) interpreting ecological data from disparate areas. Mult Scler Relat Disord 2018;21:A3-5.

3 D'Amato G, Holgate ST, Pawankar R, et al. Meteorological conditions, climate change, new emerging factors, and asthma and related allergic disorders. A statement of the world allergy organization. World Allergy Organ J 2015;8:25.

4 Reinmuth-Selzle K, Kampf CJ, Lucas K, et al. Air pollution and climate change effects on allergies in the Anthropocene: abundance, interaction, and modification of allergens and adjuvants. Environ Sci Technol 2017;51:4119-41.

5 Smoldovskaya O, Feyzkhanova G, Voloshin S, et al. Allergenspecific IgE and IgG4 patterns among patients with different allergic diseases. World Allergy Organ J 2018;11:35.
6 Kiotseridis $\mathrm{H}$, Cilio CM, Bjermer L, et al. Grass pollen allergy in children and adolescents-symptoms, health related quality of life and the value of pollen prognosis. Clin Transl Allergy 2013;3:19.

7 Gray CL, Levin ME, du Toit G. Egg sensitization, allergy and component patterns in African children with atopic dermatitis. Pediatr Allergy Immunol 2016;27:709-15.

8 Wakamiya S, Matsune S, Okubo K, et al. Causal relationships among pollen counts, Tweet numbers, and patient numbers for seasonal allergic rhinitis surveillance: retrospective analysis. J Med Internet Res 2019;21:e10450.

9 Pomés A, Chapman MD, Wünschmann S. Indoor allergens and allergic respiratory disease. Curr Allergy Asthma Rep 2016;16:43.

10 Hose AJ, Depner M, Illi S, et al. Latent class analysis reveals clinically relevant atopy phenotypes in 2 birth cohorts. J Allergy Clin Immunol 2017;139:1935-45. e12.

11 Park SC, Hwang CS, Chung HJ, et al. Geographic and demographic variations of inhalant allergen sensitization in Koreans and nonKoreans. Allergol Int 2019;68:68-76.

12 Yan YR, YH X, Zheng Q, et al. The prevalence and sex difference of allergen sensitization among adult patients with allergic diseases in Shanghai, China. Asian Pacific journal of allergy and immunology 2018.

13 Sun X, Zhao J, Wang Q, et al. Prevalence of allergen sensitization among 15,534 patients with suspected allergic diseases in Henan Province, China. Asian Pac J Allergy Immunol 2019;37:57-64.

14 Sun B-Q, Zheng P-Y, Zhang X-W, et al. Prevalence of allergen sensitization among patients with allergic diseases in Guangzhou, southern China: a four-year observational study. Multidiscip Respir Med 2014:9:2.

15 Nickel R, Kulig M, Forster J, et al. Sensitization to hen's egg at the age of twelve months is predictive for allergic sensitization to common indoor and outdoor allergens at the age of three years. $J$ Allergy Clin Immunol 1997;99:613-7.

16 Kerkhof M, Postma DS, Schouten JP, et al. Allergic sensitization to indoor and outdoor allergens and relevance to bronchial hyperresponsiveness in younger and older subjects. Allergy 2003;58:1261-7.

17 Siegfried EC, Hebert AA. Diagnosis of atopic dermatitis: mimics, overlaps, and complications. J Clin Med 2015;4:884-917.

18 Cheng L, Chen J, Fu Q, et al. Chinese Society of allergy guidelines for diagnosis and treatment of allergic rhinitis. Allergy Asthma Immunol Res 2018:10:300-53.

19 McCracken JL, Veeranki SP, Ameredes BT, et al. Diagnosis and management of asthma in adults: a review. JAMA 2017;318:279-90.

20 Warner JO, Kaliner MA, Crisci CD, et al. Allergy practice worldwide: a report by the world allergy organization specialty and training Council. Int Arch Allergy Immunol 2006;139:166-74.

21 Simons FER, Ardusso LRF, Bilò MB, et al. World allergy organization anaphylaxis guidelines: summary. J Allergy Clin Immunol 2011;127:587-93. e1-22.

22 Amat F, Soria A, Tallon P, et al. New insights into the phenotypes of atopic dermatitis linked with allergies and asthma in children: an overview. Clin Exp Allergy 2018;48:919-34.

23 Boulet LP, Turcotte H, Laprise C, et al. Comparative degree and type of sensitization to common indoor and outdoor allergens in subjects with allergic rhinitis and/or asthma. Clin Exp Allergy 1997;27:52-9.

24 Eguiluz-Gracia I, Mathioudakis AG, Bartel S, et al. The need for clean air: the way air pollution and climate change affect allergic rhinitis and asthma. Allergy 2020;75:2170-84.

25 Okamoto Y, Fujieda S, Okano M, et al. House dust mite sublingual tablet is effective and safe in patients with allergic rhinitis. Allergy 2017;72:435-43.

26 Custovic A, Sonntag H-J, Buchan IE, et al. Evolution pathways of $\lg E$ responses to grass and mite allergens throughout childhood. $J$ Allergy Clin Immunol 2015;136:1645-52.

27 Yoshida K, Adachi Y, Akashi M, et al. Cedar and cypress pollen counts are associated with the prevalence of allergic diseases in Japanese schoolchildren. Allergy 2013;68:757-63.

28 Siroux V, Boudier A, Nadif R, et al. Association between asthma, rhinitis, and conjunctivitis multimorbidities with molecular lgE sensitization in adults. Allergy 2019;74:824-7.

29 Marchetti P, Pesce G, Villani S, et al. Pollen concentrations and prevalence of asthma and allergic rhinitis in Italy: evidence from the GEIRD study. Sci Total Environ 2017;584-585:1093-9.

30 Chang A, Robison R, Cai M, et al. Natural history of Food-Triggered atopic dermatitis and development of immediate reactions in children. J Allergy Clin Immunol Pract 2016;4:229-36. e1.

31 Huby RD, Dearman RJ, Kimber I. Why are some proteins allergens? Toxicol Sci 2000;55:235-46. 
32 Cid BJ, Perez-Mateluna G, Iturriaga C, et al. Is there an association between indoor allergens and the severity of atopic dermatitis? Int $J$ Dermatol 2019;58:433-9.

33 Capristo C, Romei I, Boner AL. Environmental prevention in atopic eczema dermatitis syndrome (AEDS) and asthma: avoidance of indoor allergens. Allergy 2004;59 Suppl 78:53-60.

34 Pénard-Morand C, Raherison C, Kopferschmitt C, et al. Prevalence of food allergy and its relationship to asthma and allergic rhinitis in schoolchildren. Allergy 2005;60:1165-71.

35 Lombardi C, Canonica GW, Passalacqua G, et al. The possible influence of the environment on respiratory allergy: a survey on immigrants to Italy. Ann Allergy Asthma Immunol 2011;106:407-11.

36 D'Amato G, Cecchi L. Effects of climate change on environmental factors in respiratory allergic diseases. Clin Exp Allergy 2008:38:1264-74.

37 Worldwide variation in prevalence of symptoms of asthma, allergic rhinoconjunctivitis, and atopic eczema: ISAAC. The International study of asthma and allergies in childhood (ISAAC) Steering Committee. Lancet 1998;351:1225-32.

38 Papadopoulos NG, Agache I, Bavbek S, et al. Research needs in allergy: an EAACI position paper, in collaboration with EFA. Clin Transl Allergy 2012;2:21.

39 Torjusen EN, Diette GB, Breysse PN, et al. Dose-Response relationships between mouse allergen exposure and asthma morbidity among urban children and adolescents. Indoor Air 2013;23:268-74.

40 Gauvreau GM, Pageau R, Séguin R, et al. Dose-Response effects of TPI ASM8 in asthmatics after allergen. Allergy 2011;66:1242-8.
41 Kumar R. Association of sensitization to food and inhalant allergens in patients of asthma and rhinitis. Clin Transl Allergy 2011;1:P119.

42 Toppila-Salmi S, Huhtala H, Karjalainen J, et al. Sensitization pattern affects the asthma risk in Finnish adult population. Allergy 2015;70:1112-20.

43 Chen $\mathrm{H}, \mathrm{Li} \mathrm{J}$, Cheng L, et al. China consensus document on allergy diagnostics. Allergy Asthma Immunol Res 2021;13:177-205.

44 Feng M, Yang Z, Pan L, et al. Associations of early life exposures and environmental factors with asthma among children in rural and urban areas of Guangdong, China. Chest 2016;149:1030-41.

45 Wong GWK, Li J, Bao Y-X, et al. Pediatric allergy and immunology in China. Pediatr Allergy Immunol 2018;29:127-32.

46 Mastrorilli C, Caffarelli C, Hoffmann-Sommergruber K. Food allergy and atopic dermatitis: prediction, progression, and prevention. Pediatr Allergy Immunol 2017;28:831-40.

47 Du Toit G, Roberts G, Sayre PH, et al. Randomized trial of peanut consumption in infants at risk for peanut allergy. $N$ Engl $J$ Med 2015;372:803-13.

48 Westman M, Lupinek C, Bousquet J, et al. Early childhood lgE reactivity to pathogenesis-related class 10 proteins predicts allergic rhinitis in adolescence. J Allergy Clin Immunol 2015;135:1199-206.

49 Berings M, Karaaslan C, Altunbulakli C, et al. Advances and highlights in allergen immunotherapy: on the way to sustained clinical and immunologic tolerance. J Allergy Clin Immunol 2017;140:1250-67. 